\title{
OPTIMIZATION OF MIXING CONDITIONS FOR SILICA-REINFORCED NATURAL RUBBER TIRE TREAD COMPOUNDS
}

\author{
By W. Kaewsakul ${ }^{1,2}$, K. Sahakaro ${ }^{1,2}$, W. K. Dierkes ${ }^{2}$, J. W. M. Noordermeer ${ }^{2 *}$ \\ ${ }^{1}$ Centre of Excellence in Natural Rubber Technology (CoE-NR), Department of Rubber \\ Technology and Polymer Science, Faculty of Science and Technology, \\ Prince of Songkla University, Pattani 94000, Thailand \\ ${ }^{2}$ Department of Elastomer Technology and Engineering, University of Twente, P.O. Box 217, \\ 7500 AE Enschede, the Netherlands
}
Presented at the Fall $180^{\text {th }}$ Technical Meeting of the Rubber Division of the American Chemical Society, Inc.
Cleveland, $\mathrm{OH}$

October 11-13, 2011

ISSN: 1547-1977

* Speaker 


\begin{abstract}
The dump temperature and mixing interval between rubber, silica and silane coupling agent for silica-filled natural rubber (NR) tire tread compounds using bis-triethoxysilylpropyl tetrasulfide (TESPT) as silane were optimized. The dump temperature turns out to be the key parameter governing the properties of the silica-filled NR compounds. The increase in viscosity of the compounds by changing the dump temperature from $100-150^{\circ} \mathrm{C}$ indicates that inevitably some cross- linking of NR occurs by sulfur contained in TESPT, simultaneous with the silanization reaction between silica and silane. However, the viscosity decreases again when dump temperatures above $150^{\circ} \mathrm{C}$ are applied, indicating a dominant occurrence of degradation of the NR-molecules. The results are in good agreement with bound rubber contents. The overall properties indicate that a dump temperature in the range of $135-150^{\circ} \mathrm{C}$ and a silica-silane-rubber mixing interval of 10 minutes are the most appropriate mixing conditions for silica-filled NR compounds with TESPT as coupling agent.
\end{abstract}

Keywords: silica; natural rubber; silane; reinforcement; mixing 


\section{INTRODUCTION}

Natural rubber (NR) is a renewable material which combines excellent mechanical and dynamic properties, and its use covers a wide variety of applications, mostly in the form of filler-reinforced vulcanizates. The commonly used reinforcing fillers in rubber compounds are carbon black and silica. Replacement of carbon black by silica is growing, especially in the tire industry since the introduction of the "Green Tire Technology” by Michelin in $1992 .^{1}$ Silica significantly reduces rolling resistance and improves wet traction of tire tread compounds compared to carbon black. ${ }^{2}$ However, a major drawback of using silica are difficulties in processing which come from the polarity difference between silica and rubber.

The polar nature of silica negatively affects its compatibility with non-polar elastomers. The silica surface is acidic with a number of silanol groups. Hence, it forms strong hydrogen bonds or reacts with either basic or polar materials such as accelerators resulting in the adsorption of curatives by silica. In addition, strong hydrogen-bonds between the silica particles themselves result in tight silica aggregates and agglomerates causing poor dispersion of silica in rubber compounds. ${ }^{3}$ A good dispersion of filler in a rubber compound is very important for the mechanical and dynamic properties. ${ }^{3,4}$ The dispersion of silica-filled rubber compounds is generally worse compared to that of carbon black-filled ones. Moreover, when a large amount of silica is added, the viscosity substantially increases making the rubber compounds more difficult to process, and causing wear of the processing equipment. These difficulties can be overcome by use of silane coupling agents, which are able to combine chemically with silica and rubber during the mixing and vulcanization stages, respectively. ${ }^{5-7}$ As a consequence, mixing of silica-filled compounds is basically different from that of carbon black.

Mixing of rubber and silica with a silane coupling agent involves the reaction between silanol groups on the silica and ethoxy or hydroxyl groups of the silane, i.e. the silanization 
reaction. However, the efficient use of the silane as coupling agents in the silica-filled rubber compounds is rather limited, caused by side-reactions. Various mixing-processing conditions need to be optimized for silanized silica-filled compounds. ${ }^{8}$ The temperature window for mixing silica compounds is rather limited by a too low silanization rate versus the risk of scorch. High temperatures improve the silanization rate due to the temperature dependence of the reaction ${ }^{5}$ and reduction of sterical hindrance of the silylpropyl groups of the coupling agent by increased thermal mobility. ${ }^{9}$ Based on a study with SBR/BR compounds, ${ }^{10}$ the dump temperature should be in the range of $145^{\circ} \mathrm{C}$ to $155^{\circ} \mathrm{C}$ to achieve good silanization and to avoid pre-crosslinking. Furthermore, a mixing time of at least 10 minutes is needed for the silanization reaction during the first mixing step.

Most of the work in this area was focused on synthetic rubbers, in particular SBR/BR based-compounds for passenger tires. There are only a few studies dealing with silica-filled NR. The optimization of mixing conditions for silanized silica-filled NR compounds was studied by Wolff. ${ }^{11}$ The author concluded that an increase of mixing temperature and time for silica modification with silane enhances the compatibility between silica and NR through a chemical coupling bond of TESPT with the rubber. The overall properties are dependent on the extent of this interaction. However, it was stated that the in-situ modification reaction of silica with TESPT should not be considered as an optimum reaction, since the recipe was composed of only $20 \mathrm{phr}$ of silica in combination with $40 \mathrm{phr}$ of carbon black.

The present work aims at optimizing the mixing conditions, i.e. mixing temperature and silica-silane-rubber mixing interval, which may have an influence on mixing quality and silanization efficiency of silica-filled natural rubber compounds. Mooney viscosity, cure characteristics, filler-filler and rubber-filler interactions, as well as mechanical and dynamic properties of the rubber compounds and vulcanizates are evaluated. 


\section{EXPERIMENTAL}

\section{MATERIALS}

The natural rubber used was Ribbed Smoked Sheet 3 (RSS3), locally produced in Pattani (Thailand). The solution SBR (Buna VSL 5025-0 HM, Lanxess GmbH, Germany) contains $25 \%$ styrene and $75 \%$ butadiene, of which $50 \%$ in the vinyl configuration. The compounding ingredients were highly dispersible silica with cetyl trimethylammonium bromide (CTAB) specific surface area ${ }^{12} 171 \mathrm{~m}^{2} / \mathrm{g}$ (Ultrasil 7005, Evonik GmbH, Germany), bis-triethoxysilylpropyltetrasulfide (TESPT) with sulfur content of approximately 22 wt.-\% (Zhenjiang Wholemark Fine Chemicals, China), treated distillate aromatic extract or TDAE oil (Vivatec 500, Hansen \& Rosenthal, Germany), zinc oxide (Global Chemical, Thailand), stearic acid (Imperial Chemical, Thailand), polymerized 2,2,4-trimethyl-1,2-dihydroquinoline or TMQ, diphenylguanidine or DPG and N-cyclohexyl-2-benzothiazolesulfenamide or CBS (all from Flexsys, Belgium), and sulfur (Siam Chemical, Thailand).

\section{COMPOUND PREPARATION}

The compound recipe used for this study is shown in Table I. The amounts of TESPT and DPG applied in this recipe were based on the CTAB specific surface area of the silica according to Equation (1) and (2) as suggested by Guy et al. ${ }^{13}$ :

$$
\begin{aligned}
& \text { Amount of TESPT (phr) }=0.00053 \times \text { Q x CTAB } \\
& \text { Amount of DPG (phr) }=0.00012 \times \text { Q } \times \text { CTAB }
\end{aligned}
$$

where $\mathrm{Q}$ is the silica content (phr) and CTAB is specific surface area of the silica used $\left(\mathrm{m}^{2} / \mathrm{g}\right)$.

The mixing was performed using an internal mixer with a mixing chamber of $500 \mathrm{~cm}^{3}$ (Chareon Tut Co., Ltd., Thailand). The mixer was operated at a fill factor of $70 \%$ and a rotor speed of $60 \mathrm{rpm}$. Initial temperature settings of the mixer were adjusted in the range of 50$140^{\circ} \mathrm{C}$ (Table II). NR was initially masticated for 2 mins. Then, half of the silica and silane were added and mixed for half the duration of the silica-silane-rubber mixing interval, i.e.: 
2.5, 5, 7.5 and 10 mins, prior to adding the second half of silica and silane together with TDAE oil. The mixing was then continued to the full intervals, i.e.: 5, 10, 15 and 20 mins. Subsequently, the other ingredients: ZnO, Stearic acid, TMQ and DPG, except CBS and sulfur, were added and mixed for 3 mins. The compounds were then dumped, sheeted out on a two-roll mill, and kept overnight prior to incorporation of CBS and sulfur on a two-roll mill.

Mixer temperature settings and silica-silane-rubber mixing intervals prior to adding other chemicals were varied following the experimental design as shown in Table II. Gum or unfilled compounds were included in this study in order to determine the reinforcement parameter $\left(\alpha_{F}\right)$ from the cure characteristics; see below.

\section{MOONEY VISCOSITY AND CURE CHARACTERISTICS}

The compounds were tested for their Mooney viscosities by using a Mooney viscometer (ViscTech+, TechPro, USA) at $100^{\circ} \mathrm{C}$ with large rotor according to ASTM D1646. The value is represented as $\mathrm{ML}(1+4) 100^{\circ} \mathrm{C}$.

The cure characteristics were determined using a Moving Die Processability Tester or MDPt (TechPro, USA). The increase in torque $\left(S^{\prime}\right)$ at a temperature of $150^{\circ} \mathrm{C}$, a frequency of $0.833 \mathrm{~Hz}$ and $2.79 \%$ strain was measured for 30 minutes. The optimum vulcanization time ( $\mathrm{t}_{90}$ ) was determined and used for press-curing of the samples.

\section{CHARACTERIZATION OF FILLER-FILLER AND FILLER-RUBBER INTERACTIONS}

Reinforcement parameter. - The reinforcement parameter $\left(\alpha_{\mathrm{F}}\right)$ was calculated by using the data from the cure characteristics according to Equation (3) ${ }^{14}$ :

$$
\frac{S_{\max }^{\prime}-S_{\min }^{\prime}}{S^{\prime 0}{ }_{\max }-S^{\prime 0}{ }_{\min }}-1=\alpha_{F}\left(\frac{m_{F}}{m_{P}}\right)
$$

where $S_{\text {max }}^{\prime}-S_{\text {min }}^{\prime}=$ torque difference of the silica filled rubber; $\mathrm{S}^{\prime 0}{ }_{\max }-\mathrm{S}^{\prime 0}{ }_{\min }=$ torque difference of the corresponding gum or unfilled compound; $\mathrm{m}_{\mathrm{F}} / \mathrm{m}_{\mathrm{P}}=$ filler loading, where $\mathrm{m}_{\mathrm{F}}$ and $\mathrm{m}_{\mathrm{P}}$ correspond to the mass fractions of filler and polymer, respectively. The 
reinforcement parameter, $\alpha_{F}$ turns out to be a filler specific feature, independent of the cure system, and closely related to the morphology of the filler in the compound. ${ }^{14}$

Flocculation rate constant. - Silica flocculation can be observed by following the changes of the storage modulus of compounds at low strain amplitude during thermal annealing. ${ }^{15}$ In order to calculate the flocculation kinetics of the silica, the storage modulus at $0.56 \%$ strain amplitude can be monitored during heating at $100^{\circ} \mathrm{C}$ for 12 mins by using the Moving Die Processability Tester, according to Mihara et al. ${ }^{16}$ The degree of flocculation (x) can be expressed by the ratio of the Payne effect at time $t$ and at infinite time:

$$
x=\frac{G^{\prime}(t)-G^{\prime}(i)}{G^{\prime}(f)-G^{\prime}(i)}
$$

where $G^{\prime}(t)$ is the storage modulus at $0.56 \%$ strain amplitude after heating time $t ; G^{\prime}(i)$ is the storage modulus after preheating for 1 minute; $G^{\prime}(f)$ is the storage modulus at infinite time, taken as 12 minutes in order to reduce measuring time.

As mentioned by Bohm and Nguyen, ${ }^{15}$ silica flocculation can be experimentally described as a first order reaction for which the kinetics can be described by a simple model equation. Mihara et al. ${ }^{16}$ take this information and apply the following equation to calculate the flocculation rate constant $\left(\mathrm{k}_{\mathrm{a}}\right)$.

$$
k_{a}=\frac{\ln \left(1-x_{1}\right)-\ln \left(1-x_{2}\right)}{t_{2}-t_{1}} \quad\left[\mathrm{~s}^{-1}\right]
$$

where $\mathrm{k}_{\mathrm{a}}$ is the rate constant; $\mathrm{t}$ is the heating time; $\mathrm{x}$ is the degree of flocculation; 1 and 2 refer to different heating times t.

Payne effect. - Storage shear moduli $\left(\mathrm{G}^{\prime}\right)$ of compounds cured to their t95 at $150^{\circ} \mathrm{C}$ were measured under shear deformation using a Rubber Process Analyzer (RPA, Alpha Technologies, USA). A strain sweep test was done in the range of $0.56-100 \%$ strain at 0.50 $\mathrm{Hz}$ and $100^{\circ} \mathrm{C}$ 
Bound rubber content. - Bound rubber measurements were carried out both with and without ammonia treatment. The ammonia treatment was done in order to cleave the physical linkages between rubber and silica, so that the true chemically bound rubber could be determined. ${ }^{17}$ The procedure adopted for the bound rubber measurement was as follows:

- 0.2 g of sample, i.e. uncured masterbatch (without curatives), was put into a metal cage and immersed in $20 \mathrm{ml}$ of toluene for $72 \mathrm{~h}$ at room temperature. Toluene was renewed every $24 \mathrm{~h}$.

- The sample was removed from the toluene, dried at $105^{\circ} \mathrm{C}$ for $24 \mathrm{~h}$.

- The sample was immersed again in $20 \mathrm{ml}$ of toluene for $72 \mathrm{~h}$ at room temperature in either a normal or an ammonia atmosphere in order to cleave the physical linkages. Toluene was renewed every $24 \mathrm{~h}$.

- The sample was dried at $105^{\circ} \mathrm{C}$ for $24 \mathrm{~h}$ and weighed.

The bound rubber content was calculated according to Equation (6) ${ }^{17}$ :

$$
\text { Bound rubber content }(\%)=\frac{W_{f g}-W_{f}}{W_{p}}
$$

where $\mathrm{W}_{\mathrm{fg}}$ is the weight of silica with the bound rubber attached; $\mathrm{W}_{\mathrm{f}}$ is the weight of silica in the specimen; $\mathrm{W}_{\mathrm{p}}$ is the weight of polymer in the specimen.

\section{VULCANIZATION AND MEASUREMENT OF TENSILE AND TEAR PROPERTIES}

The compounds were press vulcanized at $150^{\circ} \mathrm{C}$ to $t_{90}$. The vulcanized sheets having a thickness of about $2 \mathrm{~mm}$ were die-cut to dumbbell shaped specimens for tensile tests and to angle shape specimens (die type C) for tear tests. The tests were performed at a crosshead speed of $500 \mathrm{~mm} / \mathrm{mins}$ according to ASTM D412 and ASTM D624, respectively, using a Hounsfield Tensile Tester. The mean values of tensile and tear properties taken from five specimens are reported. 


\section{DETERMINATION OF DYNAMIC MECHANICAL PROPERTIES}

The vulcanizates cured to their $t_{95}$ at $150^{\circ} \mathrm{C}$ in the RPA were tested for dynamic mechanical properties using a frequency sweep test. The frequencies were varied in a range of $0.05-33 \mathrm{~Hz}$ at a fixed strain and temperature of $3.49 \%$ and $60^{\circ} \mathrm{C}$, respectively.

\section{CURE CHARACTERISTICS OF NR AND SBR COMPOUNDS IN THE PRESENCE OF}

$$
\text { TESPT AND DPG (WITHOUT CBS AND SULFUR) }
$$

In order to explain the difference in change of Mooney viscosities with dump temperature of silica-filled NR compounds in comparison with previous experience with SBR compounds, ${ }^{10}$ two additional compounds were prepared. These compounds were composed of rubber with only TESPT and DPG at amounts of 5.0 and $1.5 \mathrm{phr}$, respectively. The compounds were prepared using a two-roll mill; rubber was milled for 6 mins, then DPG was added and mixed for 2 mins, and TESPT was subsequently incorporated and mixed for 2 mins. The compounds were sheeted out to a thickness of about $0.5 \mathrm{~cm}$, and kept overnight prior to testing.

The cure characteristics of these compounds were analyzed by using the RPA with a frequency of $0.833 \mathrm{~Hz}$ and strain $2.79 \%$ for 12 mins. The testing temperature was varied from $120-180^{\circ} \mathrm{C}$ with an increment of $10^{\circ} \mathrm{C}$ for each separate test.

\section{RESULTS AND DISCUSSION}

\section{PROCESSING PROPERTIES}

Mixing temperatures and torques. - The initial mixer temperatures settings and silicasilane-rubber mixing intervals prior to the addition of other chemicals were varied so that the influence of different dump (end) temperatures on the silica-filled NR compounds could be evaluated. The dump temperatures as function of initial temperature settings and silica-silanerubber mixing intervals of the silica-filled NR compounds, in comparison with those of gum compounds, are shown in Figure 1 and 2, respectively. By increasing the initial mixer 
temperature setting (Figure 1), the dump temperatures of both filled and gum compounds increase linearly. The filled compound shows a significantly higher dump temperature than that of the gum compound, attributed to the influence of hydrodynamic effects leading to higher shear forces generated during mixing. By choosing the initial mixer temperature settings in the range of $50-140^{\circ} \mathrm{C}$, dump temperatures in the range of $90-170^{\circ} \mathrm{C}$ could be obtained. Considering the different silica-silane-rubber mixing intervals of filled and gum compounds (Figure 2), longer periods clearly give higher dump temperatures for both compounds, and the filled compounds, have again higher dump temperatures than the gum compounds.

Figure 3 shows typical torque curves during mixing of silica-filled NR compounds prepared by adjusting the initial temperature setting in order to reach different dump temperatures, as they are indicated in the figure. The relation between dump temperatures and initial mixer temperature settings are given in Figure 4. The torque curves show quite different behaviors at different mixing times. Higher mixer temperature settings correspond to lower mixing torques in the range of $0-600 \mathrm{~s}$ mixing time, as depicted also in Figure 4: the torque average at $300 \mathrm{~s}$ substantially decreases with increasing mixer temperature setting. This is commonly the result of lower mixture viscosity due to the higher temperature. However, for mixing times larger than $600 \mathrm{~s}$, a crossover of the curves can be observed in Figure 3. Figure 4 shows that the mixing torque at $720 \mathrm{~s}$ increases with increasing mixer temperature setting to reach a maximum for a temperature setting of $110^{\circ} \mathrm{C}$. At the end of mixing, i.e. $890 \mathrm{~s}$, the torque also displays such a maximum. There are 3 possible reactions occurring during mixing: 1) silanization, 2) premature crosslinking due to sulfur in TESPT, and 3) rubber degradation. At dump temperatures lower than $150^{\circ} \mathrm{C}$, silanization and some premature crosslinking are dominant so that the mixing torque increases at the later stage of mixing. However, at very high initial mixer temperature settings and consequent high 
compound dump temperatures, degradation of the natural rubber becomes dominant resulting in a decrease of torque.

Mooney viscosity of the compounds. - The Mooney viscosities of the silica-filled NR compounds prepared with the different mixer temperatures and silica-silane-rubber mixing intervals in comparison with those of the gum compounds are shown in Figure 5(a) and 5(b), respectively. The filled compounds show much higher viscosities than the gum compounds, attributed to the hydrodynamic effect, filler-filler and filler-rubber interactions, and possibly some premature crosslinking of the rubber caused by sulfur in the TESPT in presence of DPG accelerator. For the silica-filled compounds, the Mooney viscosities initially increase with higher dump temperature, upon which the values gradually drop off when the dump temperature is over $150^{\circ} \mathrm{C}$. This result corresponds with the change in mixing torque average (Figure 4). Furthermore, the silica-filled compounds mixed with longer silica-silane-rubber mixing intervals, i.e. longer overall mixing times give higher Mooney viscosities, given an initial mixer temperature setting, as shown in Figure 5(b). On the other hand, the Mooney viscosities of the gum compounds show composite trends, to decrease with higher mixer temperature settings and with prolonged silica-silane-rubber mixing intervals. This is while a longer mixing time between silica, silane and NR results in a higher dump temperature, as displayed in Figure 2, giving an increase in degree of silanization of the silica and possibly some premature crosslinking of the rubber. Whereas the gum compound does not involve silica-silane-rubber reactions, the higher mixing temperatures can only lead to softening and destruction of the NR molecules. For these reasons, it is important to reconfirm that was the mixer temperature setting has more of an effect than the time allocated for silanization of the silica-filled NR system, as already reported by Wolff's. ${ }^{11}$

Cure characteristic of the compounds. - The cure characteristics of the silica-filled NR compounds: scorch time $\left(\mathrm{t}_{\mathrm{c} 10}\right)$, cure time $\left(\mathrm{t}_{90}\right)$, cure rate index (CRI) as well as rheometer 
minimum torque $\left(\mathrm{S}_{\text {min }}^{\prime}\right)$, are shown in Figure 6. With higher dump temperature the scorch time and cure rate index of the silica-filled compounds slightly increase, while the optimum cure time shows no significant change. The longer scorch time enhances processing safety while the higher cure rate leads to a similar optimum cure time, i.e. better scorch safety with the same curing cycle. Moreover, the rheometer minimum torques of the compounds reach a maximum value at a dump temperature in the range of $135-150{ }^{\circ} \mathrm{C}$, which corresponds with a similar maximum in the mixing torque average at the end of compounding, i.e. $890 \mathrm{~s}$ of mixing time (Figure 4), and in the Mooney viscosity (Figure 5).

\section{SILICA DISPERSION}

Reinforcement parameter of the compounds. - Basically, a lower reinforcement parameter indicates a better dispersion of a filler in a polymer. ${ }^{14}$ In Figure 7 , the reinforcement parameters of the silica-filled NR compounds are shown as function of dump temperature. The compounds prepared with higher dump temperature show a lower reinforcement parameter, indicating a better dispersion. However, a minimum $\alpha_{F}$ is observed in the dump temperature range of $135-170{ }^{\circ} \mathrm{C}$, which agrees with the highest mixing torque average, Mooney viscosity, and minimum cure torque as displayed in Figures 4, 5 and 6(b), respectively.

Filler flocculation of the compounds. - Dispersion stability of the filler particles or filler aggregates in the rubber matrix influences the morphology of the filled rubber compounds. Reinforcing fillers, i.e. carbon black and silica, are able to flocculate caused by the poor compatibility with the rubbers and their self-association, leading to a change in morphology and consequently deterioration in the physical properties of the vulcanizates. ${ }^{15}$ It has been documented before that silica causes a greater degree of flocculation than carbon black, while silica is more polar and has a stronger self-association tendency through hydrogen bonding when compared to carbon black. ${ }^{18}$ It is worth to mention that the 
flocculation process can occur during compound storage as well as directly prior to the onset of vulcanization in the absence of shear. ${ }^{15}$ The kinetics of the flocculation process can be monitored by determination of the storage modulus during thermal annealing of a compound under a condition that represents vulcanization. The flocculation rate constant $\left(\mathrm{k}_{\mathrm{a}}\right)$ of the silica-filled NR compounds as a function of dump temperature is shown in Figure 8. This value indicates how fast the silica flocculation process develops just before crosslinking, so that the parameter can be considered to represent silica dispersion stability as well as the degree of dispersion in silica-filled rubber compounds. Generally, a lower $k_{a}$ value means a smaller tendency towards agglomeration in the rubber matrix. In other words, a lesser amount of silica flocculation corresponds to a better dispersion stability and finer morphology, presuming that silica is well dispersed during mixing. As expected, mixing till elevated dump temperature and at longer mixing times enhances the dispersion stability of silica in the NR compounds, indicated by a decrease of the flocculation rate constant. This is in agreement with the degree of dispersion indicated by the reinforcement parameter (Figure 7).

\section{BOUND RUBBER CONTENT OF THE COMPOUNDS}

The bound rubber contents of the silica-filled compounds were evaluated under two conditions, i.e. with and without ammonia treatments. The ammonia treatment was used to cleave the physical linkages formed by physical adsorption, so that only the amount of chemically bound rubber, i.e. strong filler-rubber interactions and covalent bonds, were determined. Figure 9 shows the bound rubber contents as a function of dump temperature of the compounds measured without and with ammonia treatment. It is evident that the bound rubber content measured with ammonia treatment is lower than that measured without ammonia treatment. With increasing dump temperature and larger silica-silane-rubber mixing intervals, both total and chemically bound rubber contents in the compounds significantly increase, but level off when the dump temperature exceeds $135^{\circ} \mathrm{C}$. Considering the physical 
linkages, obtained by subtracting the chemically bound rubber from the total bound rubber content (Figure 9b), the physically bound rubber of the compounds prepared at dump temperatures over $150^{\circ} \mathrm{C}$ starts to decrease, whereas the chemically bound rubber content remains unchanged. The decrease of physically bound rubber content might be attributed to the lower molecular weight of the NR-molecules after mixing. Basically, natural rubber molecules can easily be broken down by excessively high temperatures and shearing action, because it has reactive double bonds in every repeating unit along the rubber chain. Hence, under excessive mixing conditions, the NR chains are broken down leading to lower physical linkages in the compound. This phenomenon corresponds well with the decrease of Mooney viscosities at very high dump temperatures, as previously shown in Figure 5. Interestingly, the chemically bound rubber does not show any such dependence.

\section{DYNAMIC PROPERTIES OF THE COMPOUNDS AND VULCANIZATES}

The Payne effect, i.e. the storage modulus difference between small (0.56 \%) and large (100 \%) strains, analyzed with a first and second sweep, and $\tan \delta$ at $60^{\circ} \mathrm{C}$ of the silica-filled NR vulcanizates are shown as a function of dump temperature in Figure 10. By increasing the dump temperature and mixing time, the Payne effect as a measure of filler-filler interaction decreases, even in the second sweep test (Figure 10a). However, for dump temperatures above $135^{\circ} \mathrm{C}$, there is no further change of the Payne effect. Regarding the tan $\delta$ at $60^{\circ} \mathrm{C}$ of the vulcanizates (Figure 10b), which is commonly used as an indication of rolling resistance of tires for which a lower value indicates a lower rolling resistance or less fuel consumption, ${ }^{2}$ the compounds prepared with higher dump temperature and longer silica-silane-rubber mixing interval have lower $\tan \delta$ at $60^{\circ} \mathrm{C}$. The reduction of $\tan \delta$ at $60^{\circ} \mathrm{C}$ levels off for dump temperatures above $135^{\circ} \mathrm{C}$. 


\section{MECHANICAL PROPERTIES OF THE VULCANIZATES}

Figure 11 shows the tensile strength, elongation at break, reinforcement index (i.e. the ratio of the moduli at $300 \%$ and $100 \%$ elongations or M300/M100) and tear resistance of the silica-filled NR vulcanizates prepared with varying dump temperatures and silica-silanerubber mixing intervals. With varying dump temperatures and mixing times the elongation at break of the NR vulcanizates remains more or less the same, while the tensile strength slightly decreases with increasing dump temperature but shows no dependence on mixing times. The decrease of tensile strength, reinforcement index and tear resistance when the dump temperature exceeds $150^{\circ} \mathrm{C}$ is caused by the inevitable $\mathrm{NR}$ degradation under high temperature and shearing force. The degradation of NR with and without antioxidant after mixing in an internal mixer at $160^{\circ} \mathrm{C}$ and $180^{\circ} \mathrm{C}$ for 10 mins. was clearly demonstrated by Narathichat et al. ${ }^{19}$ Considering the reinforcement index, an increasing dump temperature and silica-silane-rubber mixing interval lead to an optimum at $135^{\circ} \mathrm{C}$; thereafter the values gradually decrease when the dump temperature exceeds $150^{\circ} \mathrm{C}$. A change of tear resistance of the vulcanizates with varying dump temperatures and mixing times displays the same sort of dependence as that of the reinforcement index.

\section{COMPETITIVE REACTIONS BETWEEN SILANIZATION, PREMATURE}

\section{CROSSLINKING AND DEGRADATION IN TESPT-SILICA-FILLED NR COMPOUNDS}

With respect to the change of the NR compound viscosities with dump temperature, as reflected in the final mixing torques, Mooney viscosities and rheometer minimum torques in Figure 4, 5 and 6(b) respectively, each separate property reveals the same trend. With increasing mixing temperatures, the compound viscosities initially increase, then reach a maximum for a dump temperature range of $135-150^{\circ} \mathrm{C}$. For dump temperatures above $150^{\circ} \mathrm{C}$, the compound viscosity drops. This phenomenon is different from the work reported by Wolff, $^{11}$ in which a steady decrease of viscosity with increasing dump temperature from 110 
to $170^{\circ} \mathrm{C}$ for silica-filled NR compounds was observed. However, it should be noted that only $20 \mathrm{phr}$ of silica was used in combination with $40 \mathrm{phr}$ of carbon black in that work. In the case of silica-TESPT filled SBR/BR compounds, Reuvekamp et al. ${ }^{10}$ reported a rather constant viscosity with increasing dump temperatures from $120-150^{\circ} \mathrm{C}$, but an increased Mooney viscosity when dump temperatures above $150^{\circ} \mathrm{C}$ were obtained, caused by premature scorch of the rubber by sulfur contained in the TESPT. It is clear that the NR and SBR/BR compounds display remarkably opposite trends of compound viscosities with varying mixing conditions.

The mixing torque can be used as an indication for what is happening. During mixing times of 120-720 s in Figure 3 which represent the first and second incorporations of silica, silane, and processing oil, the decrease in the mixing torques with increasing temperature, especially after the first incorporation, is due to several factors. These include softening of the rubber at high temperature, and the breakdown of NR chains and silica structures by the mixing temperature due to mechanical energy input, in combination with the hydrophobation effect of the TESPT silica surface modification. However, interestingly, a crossover of mixing torques is noticed at the final stage of mixing. It demonstrates that, besides the silanization reaction between silica and silane, a crosslinking or scorch reaction of NR with sulfur released from TESPT is simultaneously taking place, i.e. a bond between silica-silane-rubber and rubber-rubber is created in the compound and consequently causes a rise in the compound viscosity. In order to prove this, the cure characteristic of NR and TESPT was investigated in comparison with that of SBR as shown in Figure 12. The test was performed with compounds without CBS and elemental sulfur. It is clearly seen that NR readily reacts with TESPT at a temperature as low as $120^{\circ} \mathrm{C}$ and the reaction rate increases rapidly at higher temperatures, as seen from a change of the cure curves. SBR shows a different behavior since it starts to react with TESPT at a higher temperature, i.e. $150^{\circ} \mathrm{C}$. The rheometer torque differences, commonly 
used to indicate the extent of crosslinking of both compounds are shown in Figure 13. The value for the NR+TESPT compound substantially increases from a test temperature of $120^{\circ} \mathrm{C}$ up to $150^{\circ} \mathrm{C}$, and then gradually decreases at higher temperatures: a sort of reversion. On the other hand, the torque difference for the SBR+TESPT compound remains constant till a temperature of $140^{\circ} \mathrm{C}$, and then increases rapidly when the cure temperature exceeds $150^{\circ} \mathrm{C}$. These results indicate that the viscosity of silica-TESPT filled rubber compounds significantly depends on a premature crosslinking reaction which takes place during the mixing process due to available sulfur in TESPT, in addition to the silanization reaction and the thermomechanical shearing action. In this context it is worth to mention that TESPT was first developed as a sulfur-cure accelerator with sulfur-donor properties, before it became commonly accepted as a coupling agent. ${ }^{20,21}$ Therefore, the increase of the silica-filled NR compound viscosities for dump temperatures in the range of $100-145^{\circ} \mathrm{C}$ (Figure 5) is to a large extent due to the silica-silane-NR coupling reaction that occurs during the mixing process, and this reaction reaches its maximum at a dump temperature around $135-150^{\circ} \mathrm{C}$. This premature crosslinking reaction dominates over the breakdown of rubber chains and silica structures.

As seen from Figure 5, the viscosities of the silanized silica-filled NR compounds tend to decrease again at dump temperatures above $150^{\circ} \mathrm{C}$. This may be attributed to an optimum degree of silica-rubber and rubber-rubber interactions/reactions induced by the TESPT. Furthermore, degradation of rubber chains and/or polysulfide linkages becomes prominent. This observation can be also confirmed by the change of bound rubber content in the compounds (Figure 9). The chemically bound rubber reaches a plateau at a dump temperature of approximately $135^{\circ} \mathrm{C}$, indicating that the silica-silane-rubber and rubber-rubber interactions/reactions remain intact at higher temperature and shear force. Meanwhile, the physically bound rubber content in the compounds prepared at dump temperatures over $150^{\circ} \mathrm{C}$ 
decreases somewhat, suggesting a reduction of chain entanglements or the physical network of rubber molecules due to a chain shortening by the degradation reaction.

The mixing of silica-silane and NR can not avoid this premature crosslinking when TESPT is used as coupling agent, as the NR starts to react with sulfur present in TESPT at a temperature as low as $120^{\circ} \mathrm{C}$ (Figure 13). The increased Mooney viscosity is normally an undesired processing property since it leads to processing difficulties in extrusion and calendering. Surprisingly, this phenomenon does not have an adverse effect on other properties of the compounds and vulcanizates. As illustrated in Figure 6, even better cure characteristics were obtained for compounds prepared with higher dump temperature, as indicated by the faster cure rate and longer scorch time. The improvement in cure behavior could be the result of better silanization so that all silica surfaces are well covered with silane resulting in less acidity and polarity, which in turn prevents a reduction of cure retardation and accelerator adsorption. Furthermore, when DPG is used in the recipe to enhance the silanization reaction $^{22}$ as well as to act as a secondary accelerator, the higher level of silanization could also mean that a smaller portion of CBS is adsorbed on the still uncovered silica surface, so that this accelerator is more efficiently used for the curing. The improvement of the mechanical properties with increasing dump temperature to the optimum point, i.e. in the range of $135-150^{\circ} \mathrm{C}$, especially in terms of reinforcement index (M300/M100) and tear resistance (Figure 11) is accounted for by a better silica dispersion in the NR as indicated by reinforcement parameter $\left(\alpha_{\mathrm{F}}\right)$, flocculation rate constant $\left(\mathrm{k}_{\mathrm{a}}\right)$ and Payne effect of the compounds in Figures 7, 8 and 10, respectively. This also corresponds with the higher bound rubber content which indicates a better filler-rubber interaction. The lightly crosslinked network formed at the later stage of mixing restricts the movement of dispersed silica particles. As a consequence, the re-agglomeration of silica is reduced, as depicted by a decrease of the flocculation rate constant (Figure 8). The results of this present work show a 
good agreement with the work reported by Lin et al., ${ }^{23}$ in which the compounds comprising of TESPT showed a reduction of silica flocculation when they were mixed at higher dump temperature. Based on the present results, re-agglomeration of silica/TESPT-filled NR compounds can be effectively suppressed when sufficiently high mixing temperature is used. This is not only due to better silica dispersion, higher degree of hydrophobation, greater extent of polymer-filler interaction, but also due to the lightly crosslinked network as a result of a small amount of crosslinking during mixing.

The $\tan \delta$ at $60^{\circ} \mathrm{C}$, a measure of rolling resistance of tires based on silica-filled NR, is shown to improve when the compound dump temperatures are increased and the optimum temperature is also in a range of $135-150^{\circ} \mathrm{C}$, in agreement with all other properties.

Based on our investigations on the reinforcement parameter, flocculation rate constant, bound rubber content, Payne effect, loss tangent at $60^{\circ} \mathrm{C}$ (indication for rolling resistance), and mechanical properties, the optimal mixing conditions for silica-filled NR with TESPT as a coupling agent are a dump temperature in the range of $135-150^{\circ} \mathrm{C}$, and 10 mins mixing interval of silica-silane-rubber after mastication and before the addition of the other ingredients: ZnO, Stearic acid, TMQ and DPG. The decrease of reinforcement parameter, flocculation rate constant and Payne effect combined with the increase of bound rubber content can be taken as a proof for proper silanization. However, it is worth to emphasize that the change of Mooney viscosity with dump temperature is different for the NR and SBR cases when TESPT is used. The Mooney viscosity of silica-filled NR compound increases due to sulfur in the TESPT to the maximum and thereafter decreases at higher temperatures as NR degradation starts to take place.

\section{CONCLUSIONS}

Varying initial mixer temperature settings from $50-140^{\circ} \mathrm{C}$ and mixing intervals from 5 to 20 minutes for the silica-filled NR compounds lead to the dump (end) temperatures in a 
range of $90-170^{\circ} \mathrm{C}$. The properties of both compounds and vulcanizates show a strong dependence on dump temperature since the silanization reaction and silica dispersion are key parameters in this system. The optimal mixing conditions for the silica-filled NR compound with TESPT as a coupling agent are a dump temperature in the range of $135-150^{\circ} \mathrm{C}$, and 10 mins mixing interval of silica-silane-rubber prior to addition of the other ingredients: $\mathrm{ZnO}$, Stearic acid, TMQ and DPG. Mixing performed till dump temperatures above $150^{\circ} \mathrm{C}$ leads to a decrease in vulcanizate properties as a result of NR degradation. During mixing of silicafilled NR compounds with TESPT as coupling agent, it is evident that in addition to the silanization reaction, premature crosslinking reactions take place since NR can start to react with sulfur coming from TESPT molecules at a temperature as low as $120^{\circ} \mathrm{C}$. However, this phenomenon does not have an adverse effect on the vulcanizate properties.

\section{ACKNOWLEDGEMENTS}

The authors acknowledge the financial support from the Netherlands Natural Rubber Foundation (Rubber Stichting), and would like to thank N. Gevers from Apollo Vredestein Cie. and S.S. Sarkawi for fruitful discussions.

\section{REFERENCES}

${ }^{1}$ R. Rauline (to Compagnie Generale des Etablissements Michelin-Michelin \& Cie), U.S.Patent 5227425, July 13, 1993 ; E.P. 0501227A1, Sept.2, 1992.

${ }^{2}$ H.-D. Luginsland, W. Niedermeier, Rubber World. 228, 34 (2003).

${ }^{3}$ A.I. Medalia, RUBBER CHEM. TECHNOL. 47, 411 (1974).

${ }^{4}$ M.-J. Wang, RUBBER CHEM. TECHNOL. 72, 430 (1999).

${ }^{5}$ U. Görl, A. Hunsche, A. Müller, H.G. Koban, RUBBER CHEM. TECHNOL. 70, 608 (1997).

${ }^{6}$ H.-D. Luginsland, J. Frohlich, A. Wehmeier, RUBBER CHEM. TECHNOL. 75, 563 (2002). 
${ }^{7}$ J.W. ten Brinke, P.J. van Swaaij, L.A.E.M. Reuvekamp, J.W.M. Noordermeer, Kautsch. Gummi Kunstst. 55, 244 (2002).

${ }^{8}$ W.K. Dierkes, J.W.M. Noordermeer, K. Kelting, A. Limper, Rubber World. 229, 6 (2004).

${ }^{9}$ J.E. Mark, B. Erman, F.R. Eirich, The Science and Technology of Rubber, $3^{\text {rd }}$ edition, Elsevier Academic Press, Burlington 2005, p. 424.

${ }^{10}$ L.A.E.M. Reuvekamp, J.W. ten Brinke, P.J. van Swaaij, J.W.M. Noordermeer, Kautsch. Gummi Kunstst. 55, 41 (2002).

${ }^{11}$ S. Wolff, RUBBER CHEM. TECHNOL. 55, 967 (1982).

${ }^{12}$ O. Stenzel, H.-D. Luginsland, S. Uhrlandt, A. Wehmeier (to Degussa AG). U.S. Patent 7608234, Oct. 27, 2009.

${ }^{13}$ L. Guy, S. Daudey, P. Cochet, Y. Bomal, Kautsch. Gummi Kunstst. 62, 383 (2009).

${ }^{14}$ S. Wolff, Kautsch. Gummi Kunstst. 23, 7 (1970).

${ }^{15}$ G.G.A. Bohm, M.N. Nguyen, J. Appl. Polym. Sci. 55, 1041 (1995).

${ }^{16}$ S. Mihara, R.N. Datta, J.W.M. Noordermeer, RUBBER CHEM. TECHNOL. 82, 524 (2009).

${ }^{17}$ S. Wolff, M.J. Wang, E.H. Tan, RUBBER CHEM. TECHNOL. 66, 163 (1993).

${ }^{18}$ M.-J. Wang, S. Wolff, J.-B. Donnet, RUBBER CHEM. TECHNOL. 64, 714 (1991).

${ }^{19}$ M. Narathichat, K. Sahakaro, C. Nakason, J. Appl. Polym. Sci. 115, 1702 (2010).

${ }^{20}$ F. Thum and S. Wolff, Kautsch. Gummi Kunstst. 28, 733 (1975).

${ }^{21}$ S. Wolff, Kautsch. Gummi Kunstst. 32, 760 (1979).

${ }^{22}$ C. Penot (to Michelin Recherche et Technique S.A.), U.S. Patent 6951897, Oct. 4, 2005.

${ }^{23}$ C.J. Lin, W.L. Hergenrother, E. Alexanian, G.G.A. Bohm, RUBBER CHEM. TECHNOL. 75, 865 (2002). 
TABLE I

COMPOUND FORMULATION

\begin{tabular}{lc}
\hline \multicolumn{1}{c}{ Ingredients } & Amount (phr) \\
\hline NR (RSS3) & 100.0 \\
Silica (Ultrasil 7005) & 55.0 \\
Silane (TESPT) & 5.0 \\
Process oil (TDAE) & 8.0 \\
Zinc oxide & 3.0 \\
Stearic acid & 1.0 \\
TMQ & 1.0 \\
DPG & 1.1 \\
CBS & 1.5 \\
Sulfur & 1.5 \\
\hline
\end{tabular}


TABLE II

EXPERIMENTAL DESIGN FOR OPTIMIZING MIXER TEMPERATURE AND MIXING

INTERVAL FOR SILICA-FILLED NR COMPOUNDS

\begin{tabular}{ccccc}
\hline Mixer temperature & \multicolumn{4}{c}{ Mixing interval (mins.) } \\
\cline { 2 - 5 } setting $\left({ }^{\circ} \mathrm{C}\right)$ & 5 & 10 & 15 & 20 \\
\hline 50 & $\mathrm{x}$ & $\mathrm{x}$ & $\mathrm{x}$ & $\mathrm{x}$ \\
60 & $\mathrm{x}$ & $\mathrm{x}$ & $\mathrm{x}$ & $\mathrm{x}$ \\
70 & $\mathrm{x}$ & $\mathrm{x}$ & $\mathrm{x}$ & $\mathrm{x}$ \\
80 & - & $\mathrm{x}$ & - & - \\
90 & - & $\mathrm{x}$ & - & - \\
100 & - & $\mathrm{x}$ & - & - \\
110 & - & $\mathrm{x}$ & - & - \\
120 & - & $\mathrm{x}$ & - & - \\
130 & - & $\mathrm{x}$ & - & - \\
140 & - & $\mathrm{x}$ & - & - \\
\hline
\end{tabular}

$\mathrm{x}$ is assigned to the conditions for which both gum and filled compounds were prepared. 


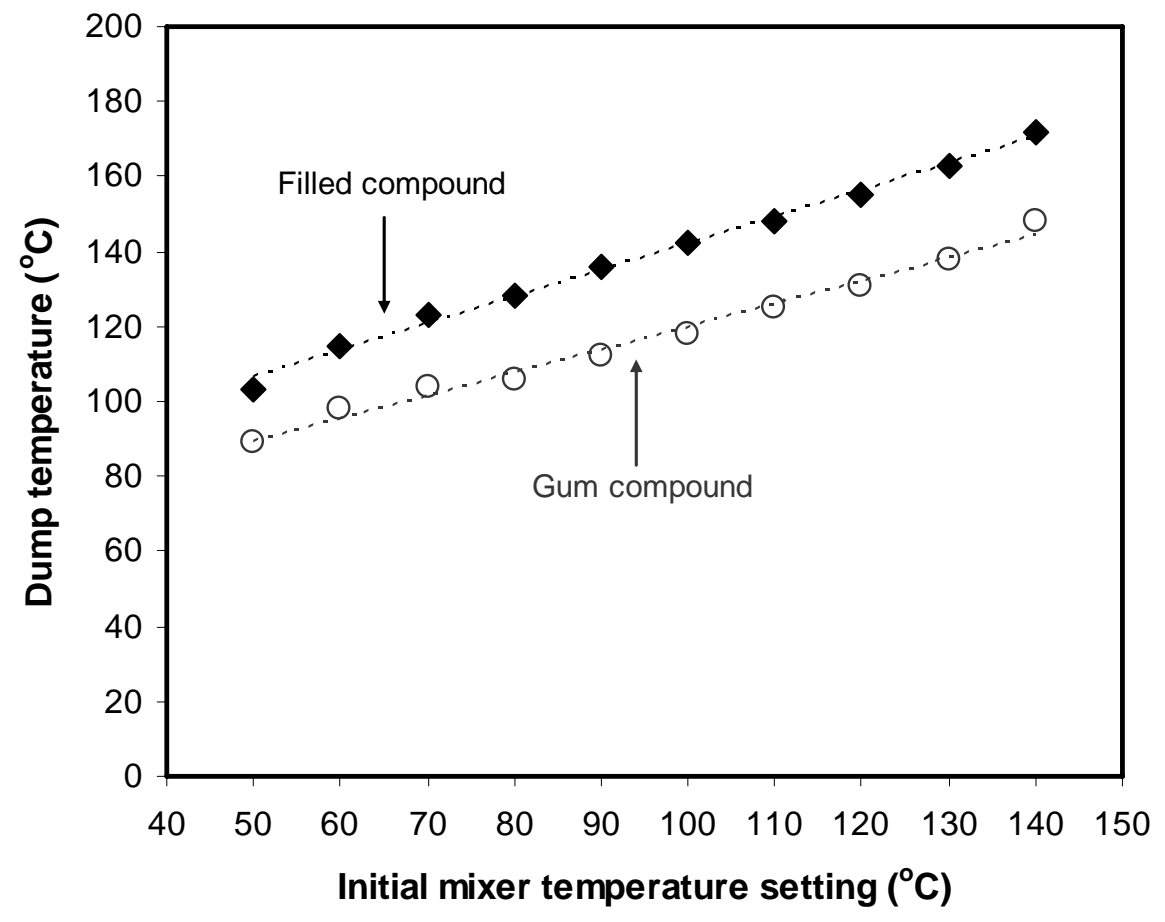

FIG. 1. - Dump temperature as a function of initial mixer temperature setting for gum and silica-filled NR compounds, with 10 mins. mixing interval for silica+silane and rubber. 


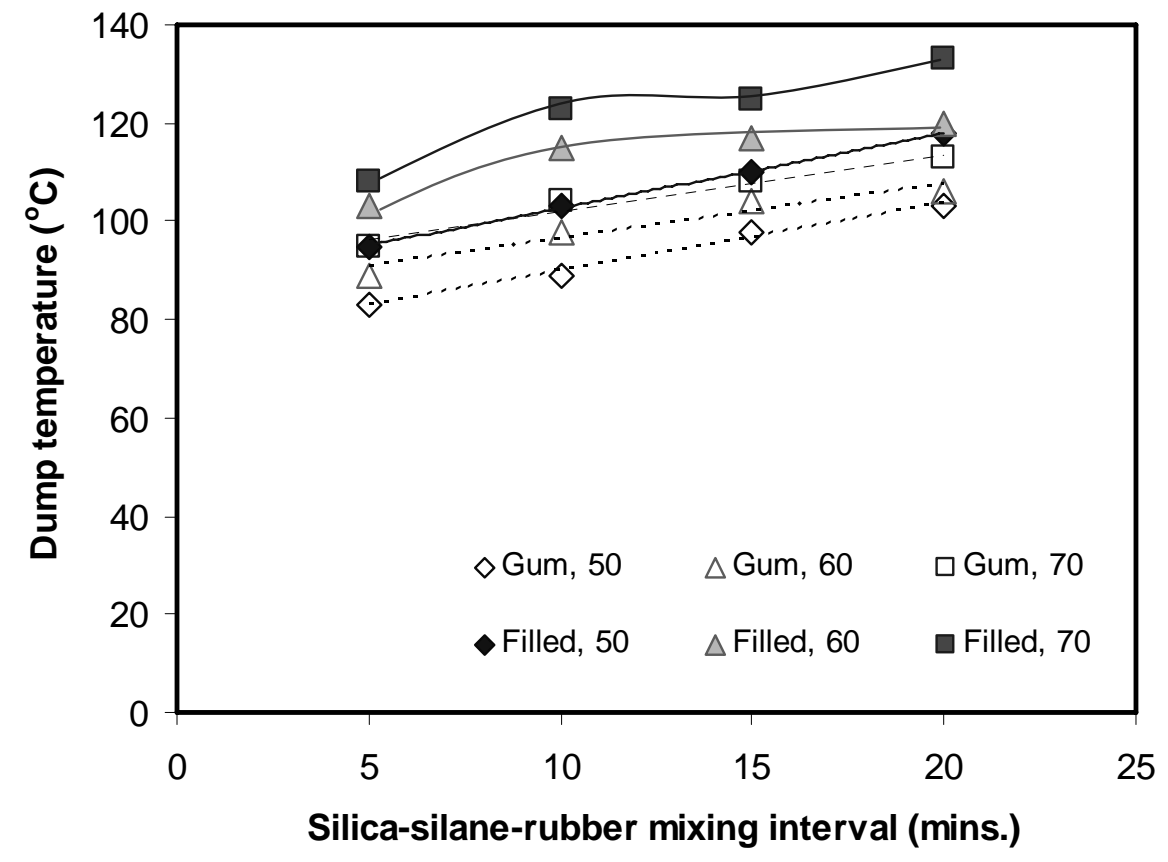

FIG. 2. - Dump temperature as a function of silica-silane-rubber mixing interval for gum and silica-filled NR compounds. The initial mixer temperature settings were varied from 50 to $70^{\circ} \mathrm{C}$, as indicated. 


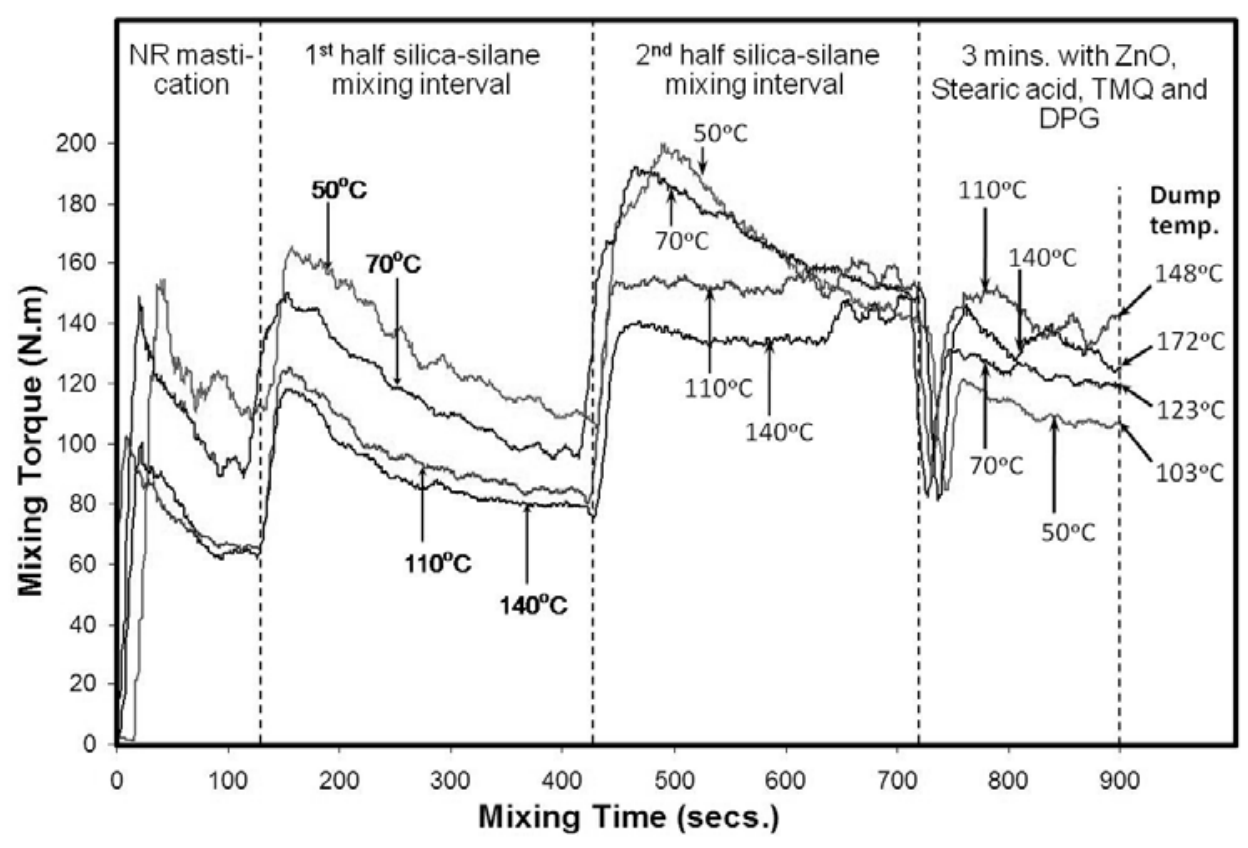

FIG. 3. - Mixing torques for silica-filled NR compounds prepared with various mixer temperature settings, as indicated for each line. The silica-silane-rubber total mixing interval was 10 mins. 


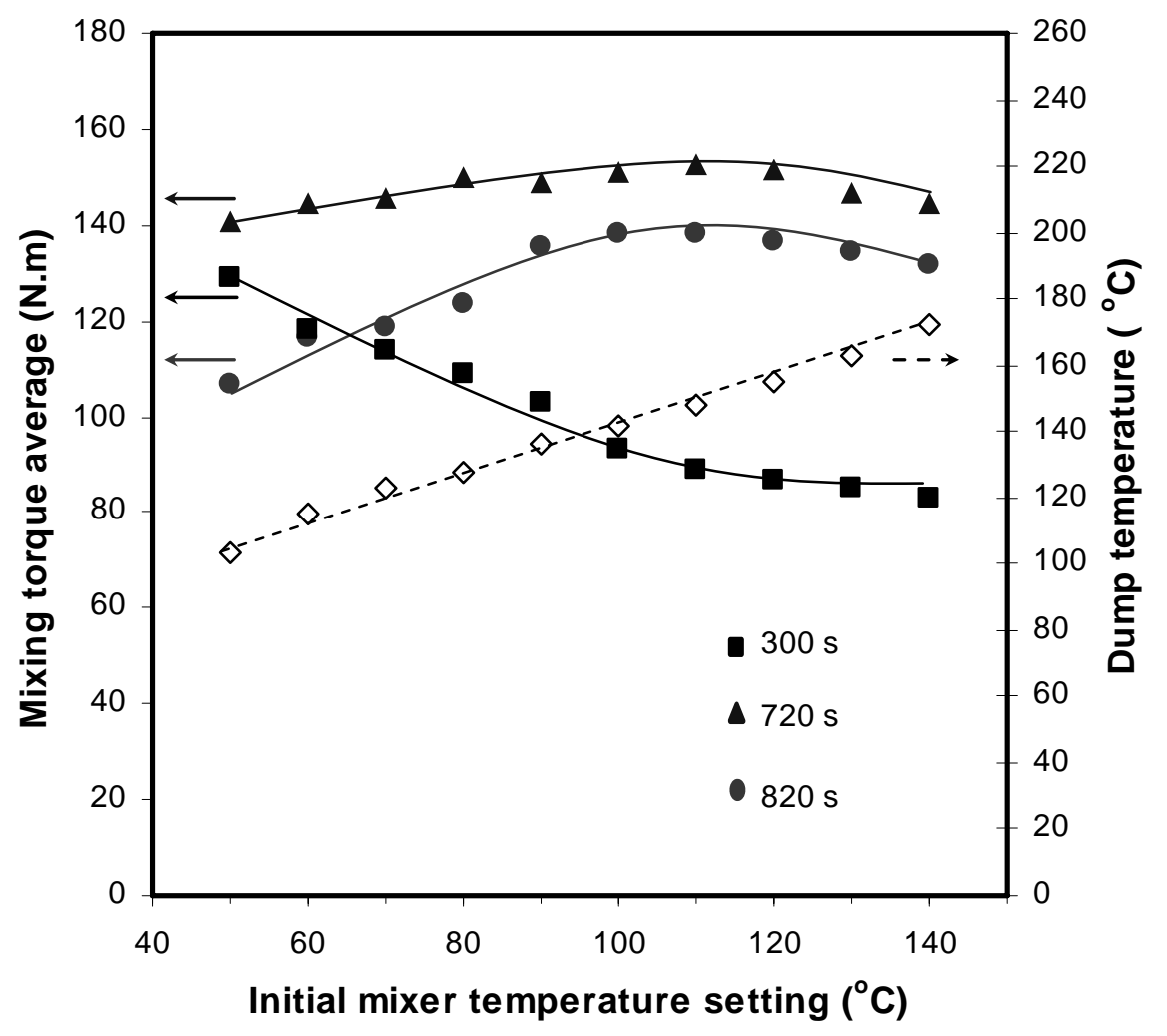

FIG. 4. - Correlation between the mixer temperature setting, mixer torque and dump temperature of silica-filled NR compounds at 300, 720 and 890 seconds when a 10 mins. silica-silane-rubber mixing interval was used. 

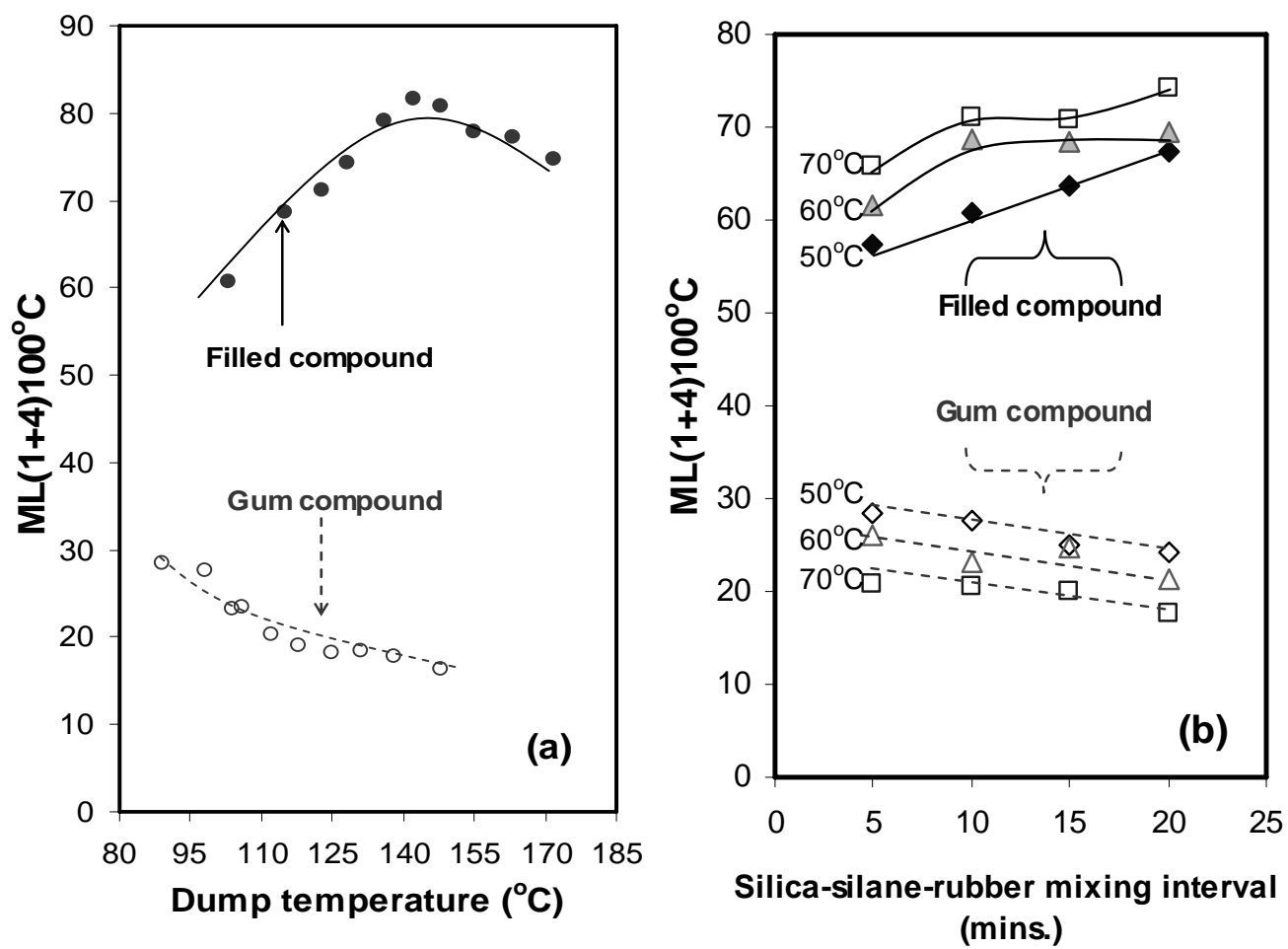

FIG. 5. - Effect of (a) dump temperature and (b) silica-silane-rubber mixing interval on Mooney viscosity of gum and silica-filled NR compounds; parameter: initial temperature settings of mixer. 

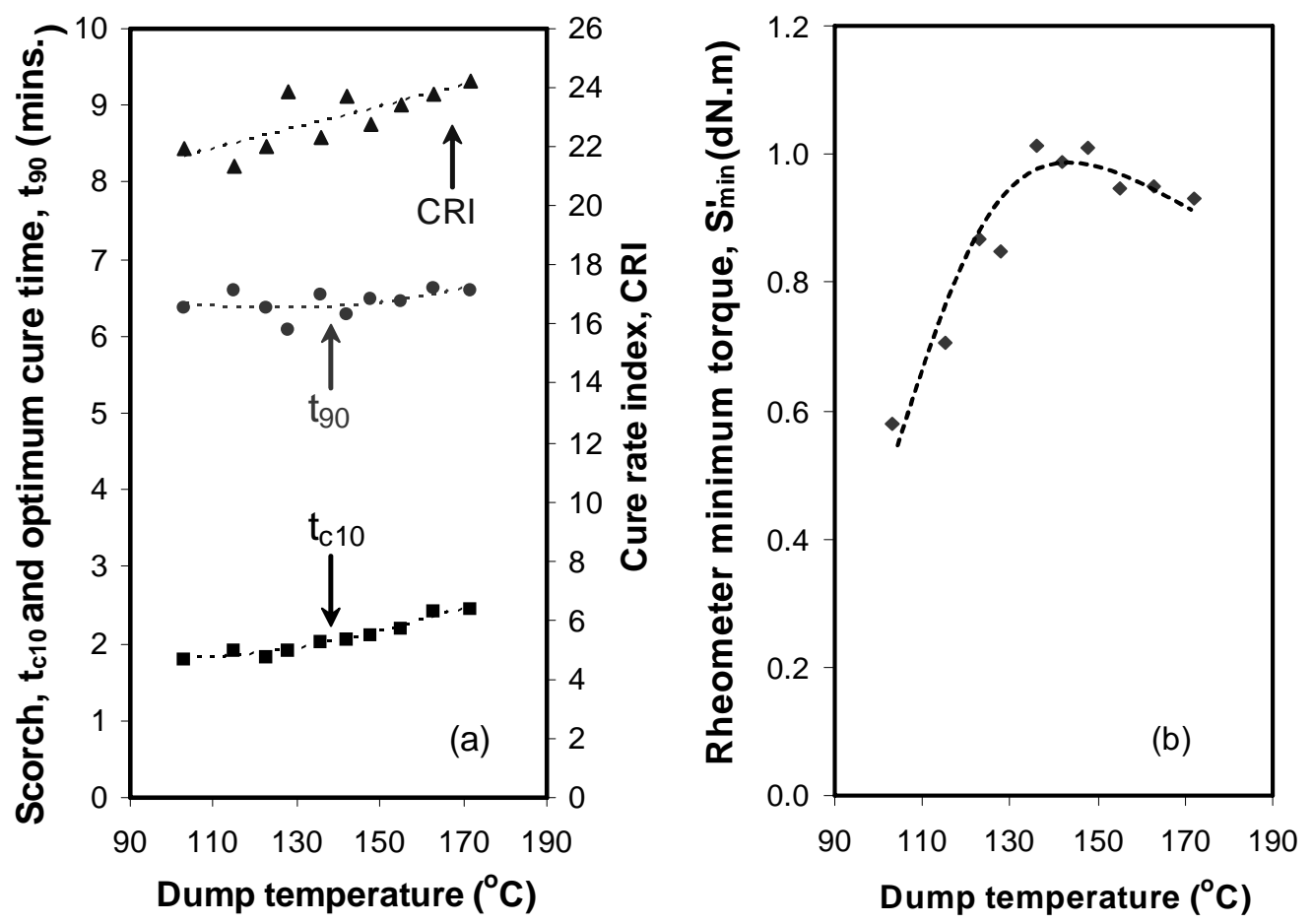

FIG. 6. - Effect of dump temperature on (a) scorch time, optimum cure time, cure rate index and (b) rheometer minimum torque of silica-filled NR compounds. 


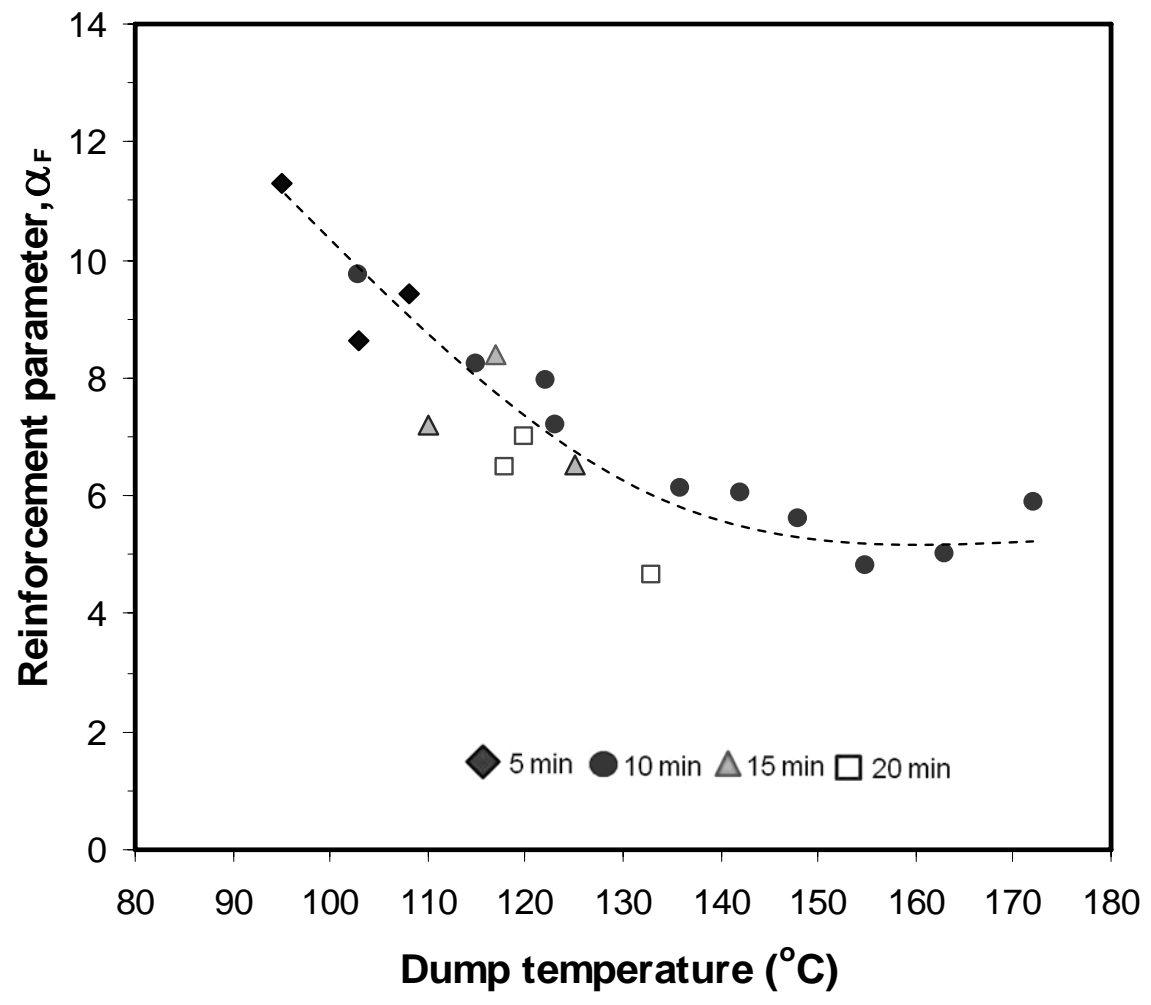

FIG. 7. — Effect of dump temperature on reinforcement parameter of silica-filled NR compounds prepared with various silica-silane-rubber mixing intervals. 


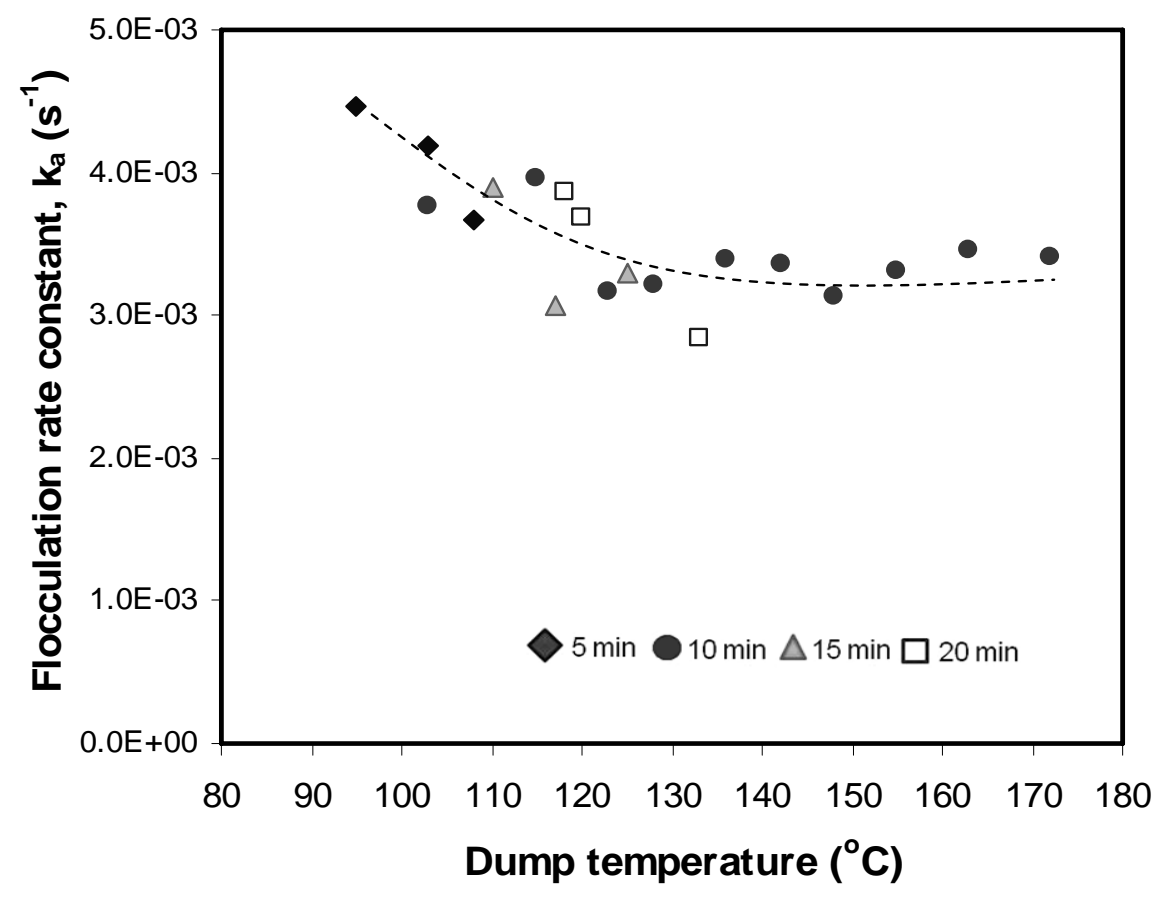

FIG. 8. - Effect of dump temperature on flocculation rate constant of silica-filled NR compounds prepared with various silica-silane-rubber mixing intervals. 

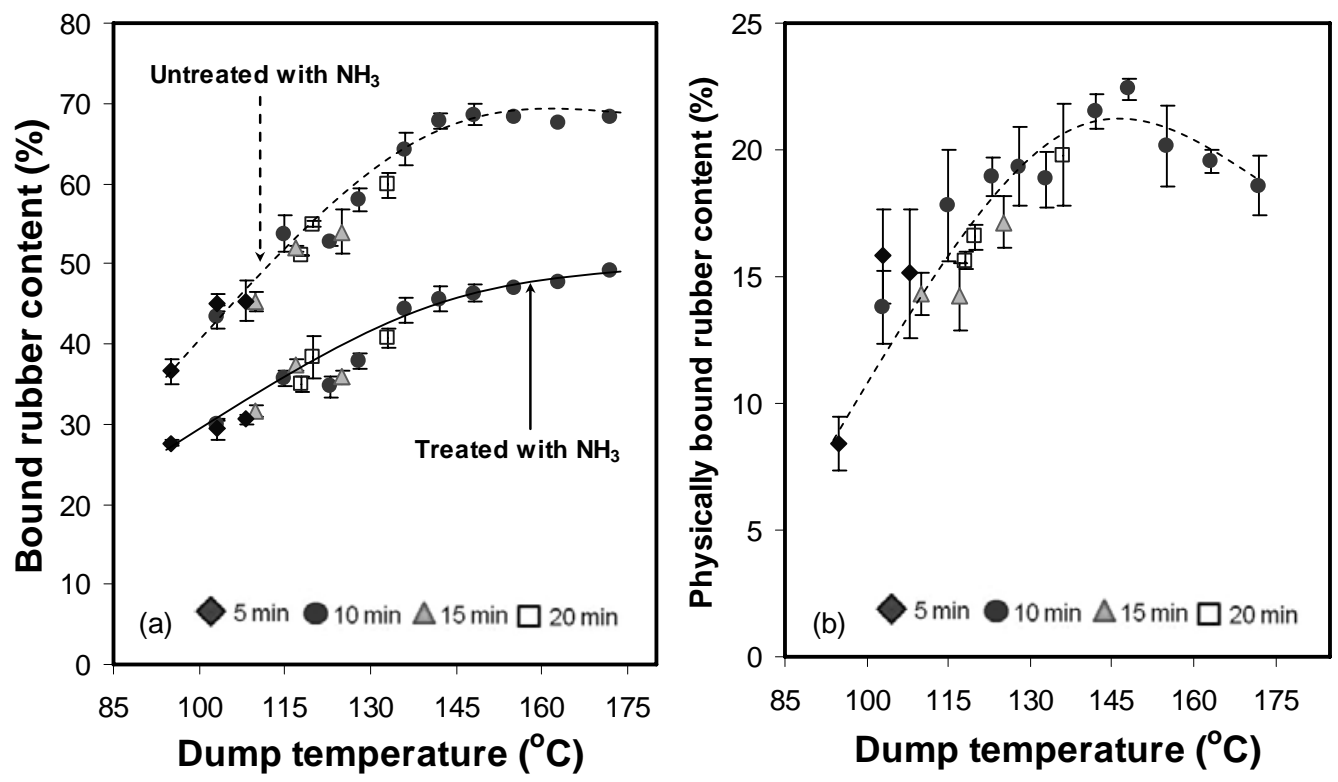

FIG. 9. - Influence of dump temperature on bound rubber contents of silica-filled NR compounds: (a) total (untreated with $\mathrm{NH}_{3}$ ) and chemically bound rubber (treated with $\mathrm{NH}_{3}$ ); and (b) physically bound rubber content. 

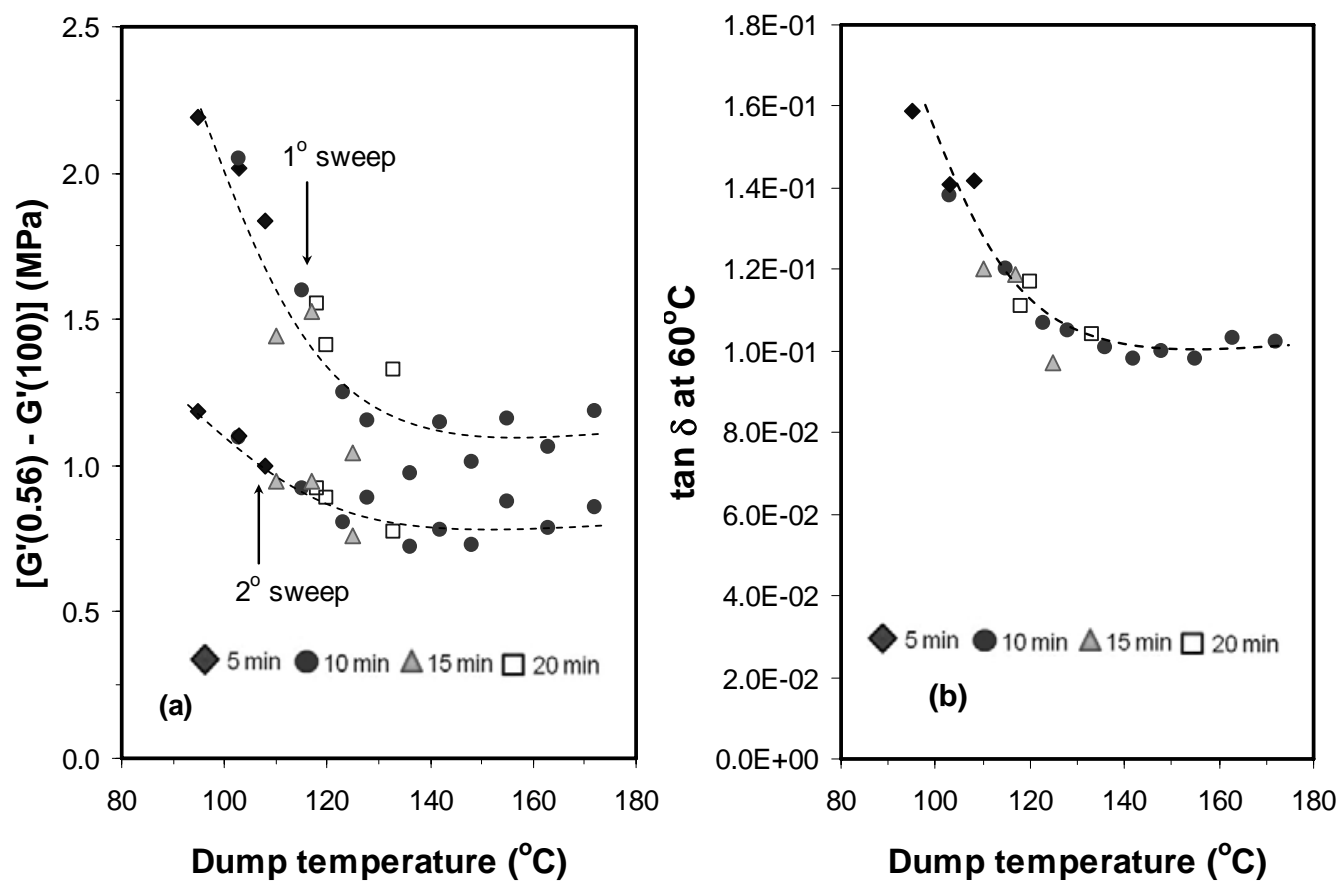

FIG. 10. — Influence of dump temperature on dynamic properties: (a) Payne effect; and (b) $\tan \delta$ at $60^{\circ} \mathrm{C}$ (frequency $10 \mathrm{~Hz}$ ) of silica-filled NR vulcanizates prepared with various silicasilane-rubber mixing intervals. 

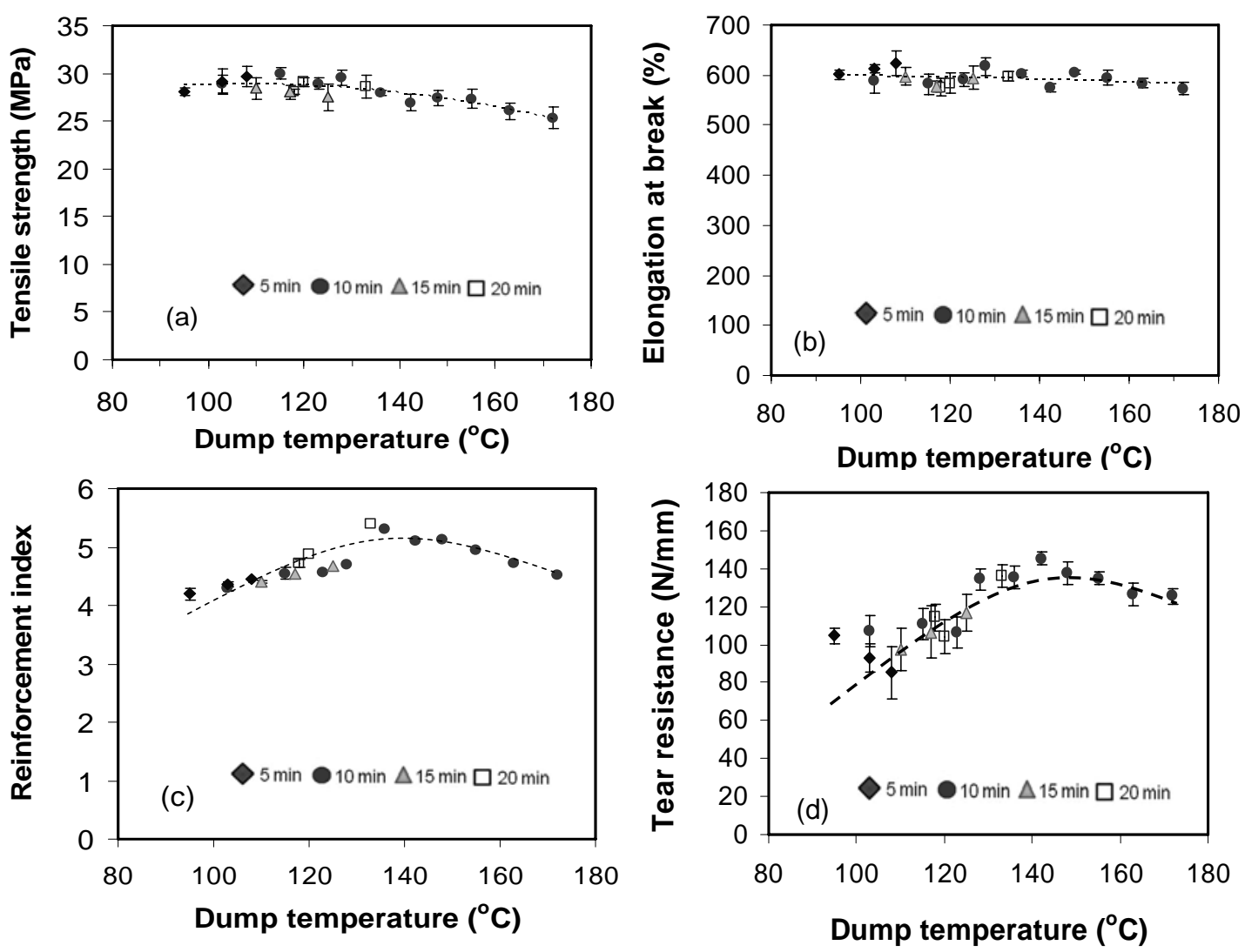

FIG. 11. - Effect of dump temperature and silica-silane-rubber mixing interval on mechanical properties of silica-filled NR vulcanizates: (a) tensile strength; (b) elongation at break; (c) reinforcement index; and (d) tear resistance. 

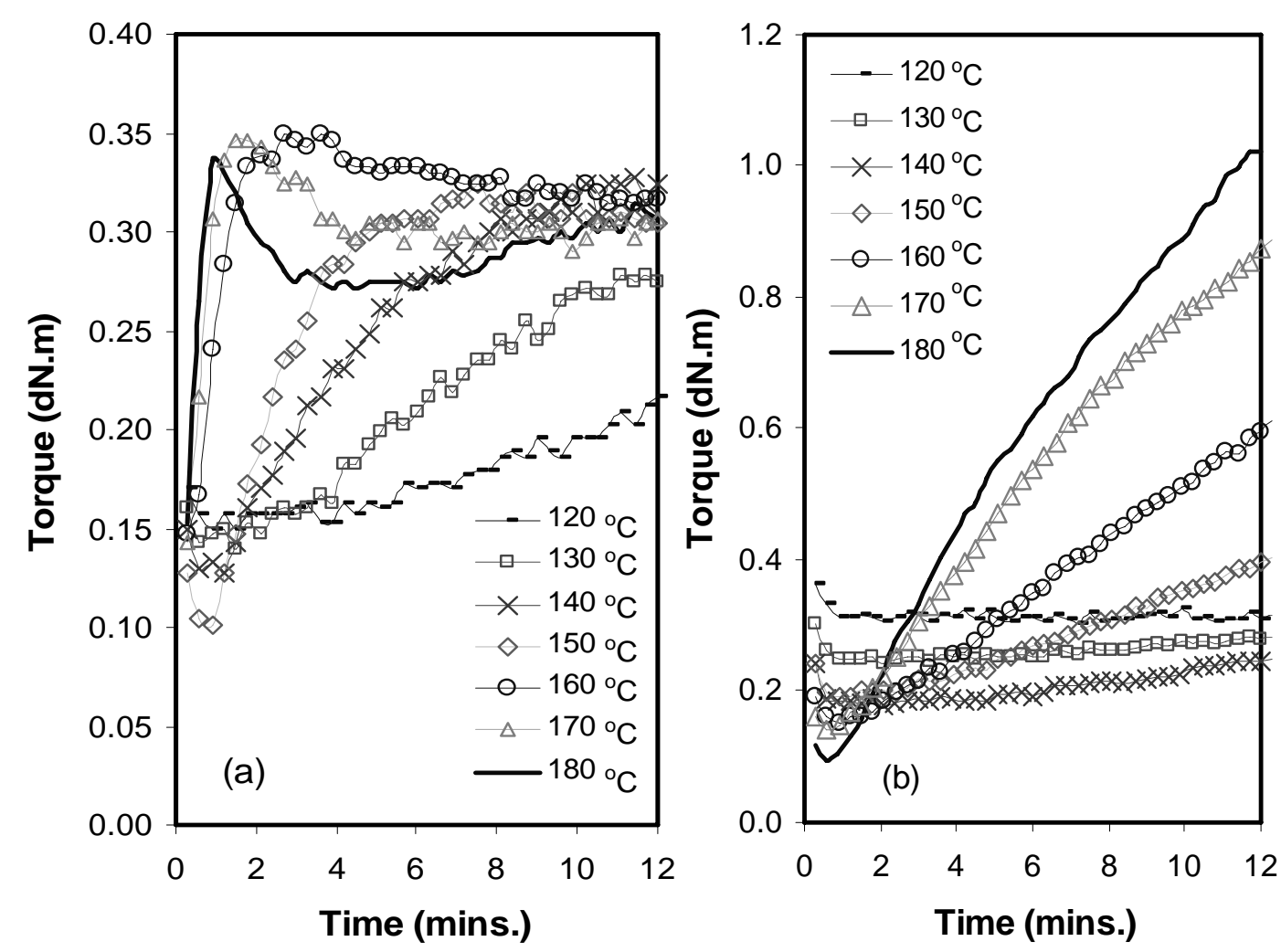

FIG. 12. - Cure characteristics of (a) NR and (b) SBR compounds, in the presence of TESPT (5.0 phr) and DPG (1.5 phr) at different cure temperatures. 


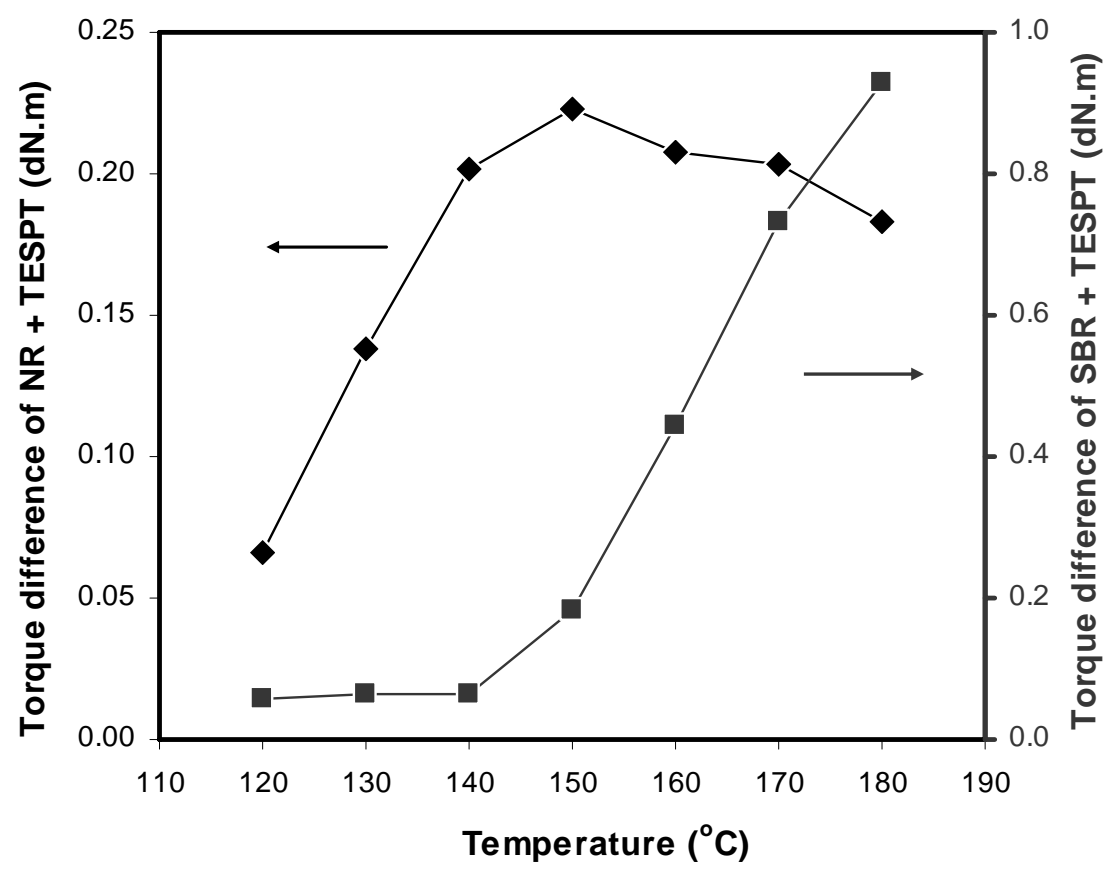

FIG. 13. - Rheometer torque difference of NR and SBR compounds as a function of cure temperature in the presence of TESPT (5.0 phr) and DPG (1.5 phr). 